\title{
CONTROLE DE PLANTAS DANINHAS E EFEITOS DE HERBICIDAS NA CULTURA DE Gladiolus
}

\section{RESUMO}

O controle de plantas daninhas e a tolerância de gladíolos, cultivares Spick and Span e White Friendship, a tratamentos herbicidas foi estudado em um experimento de campo em solo are no-argiloso.

Foram aplicados os herbicidas trifluralin e EPTC em pré-plantio com incorporação e chloroxuron, DCPA, diphenamid, pendimethalin e diuron em pré-emergência. Houve maior incidência de gramineas que foram controladas por todos os herbicidas, exceto chloroxuron, sendo o controle pelo EPTC de $83 \%$ e pelos demais, acima de $90 \%$. Para as dicotiledóneas, o controle foi na seguinte ordem decrescente: pendimethalin, chloroxuron, diuron, trifluralin, EPTC, DCPA e diphenamid. O EPTC afe tou a germinação de bulbos, causando, também, retenção de crescimento e atraso no ciclo.

No florescimento, as hastes florais foram colhidas, medidas e pesadas, verificando-se redução significativa de peso de matéria fresca com o tratamento EPTC para o cultivar Spick and Span, e com trifluralin, EPTC, chloroxuron e pendimethalin para o White Friendship.

UNITERMOS: Herbicidas, gladíolos, controle de mato.

\section{SUM MARY}

WEED CONTROL AND EFFECTS OF HERBICIDES ON GLADIOLUS.

The weed control by herbicides and their effects on gladioli was evaluated on a field experi-

\author{
R. Deuber ( ${ }^{1}$ ); L.H. Signori (2); L.A.F. Mathes (3)
}

\& R. Forster (4)

(') Pesquisador Científico, S. Figiologia.

(2) Biologista, Centro Experimental de Campinas

(3) Pesquisador Científico, S. de Floricultura

(4) Pesquisad or Científico, Centro

Experimental de Campinas.

Instituto Agronômico, Caixa Postal 28, 13.100

Campinas, Est. S. Paulo.

Trabalho apresentado no XII Seminário Brasileiro de Herbicidas e Ervas Daninhas, Fortaleza, CE, 1978.

Recebido para publicação em 20.03.79. ment on sandy-loam soil on CV Spick and Span and White Friendship.

Trifluralin and EPTC were applied pre plant incorporated and chloroxuron, DCPA, diphen amid, pendimethalin and diuron in pre emergence. Grass species were predominant in the area and were controled by all herbicides ex cept chloroxuron. Control by EPTC was of $83 \%$ and over $90 \%$ by all others. The broadleaves were controled in the following decrescent order: pendime thal in, chlo roxu ron, di ur on, triflu ralin, EPTC, DCPA and diphenamid. Only EPTC affected the sprouting of bulbs, causing also growth retention and delaying of flower set.

The flowers stems were cut off a the opening of the first flower, measured and weighted. EPTC caused significant reduction in weight of CV Spick and Span and trifluralin, EPTC, chlorox uron and pendimethalin of CV White Friendship.

KEYWORDS: herbicides, gladiolus, weed control.

\section{INTRODUÇÃO}

O cultivo de flores no Estado de São Paulo tem apresentado, nos últimos anos, um contínuo crescimento, figurando, atualmente, como atividade de considerável importância econômica. Dentre as espécies comercializadas no CEAGESP, as de maiores expressões comerciais são rosa e gladíolos $(5,9)$. 
A produção de gladíolos pela Cooperativa Agropecuária Holambra, que retem 50 a 70 por cento da oferta é em torno de 20 mil dúzias diárias, ocupando área de 500 ha, com estimativa de exportação de 1.000 caixas (30 maços de 10 flores por caixa) por semana para o ano 1977-78 (9).

O plantio é geralmente feito a cada 15 dias e há necessidade de se manter a cultura ao limpo, com capinas feitas manualmente. O emprego de herbicidas está tomando certo vulto (11), embora não haja ainda pesquisa de seu uso em nossas condições. $O$ uso seguro e eficiente de diferentes herbicidas para gladíolos já foi comprovado em estudos realizados em outros países $(1,2,3,6,7$, $8,10,12,13,14,15)$.

Objetivando-se iniciar o estudo de herbicidas em gladiolos, foi instalado um experimento de campo, em que se aplicaram diferentes compostos isoladamente para observar a eficiência do controle de plantas daninhas e a sua toler ância pela cultura.

\section{MATERIAL E MÉTODOS}

Foi instalado um experimento de campo em gladíolos (Gladiolus) cultivares Spick and Span e White Friendship, doravante chamadas rosa crespa e branca crespa, respectivamente. Utili zouse uma área do Centro Experimental de Campinas, de latossolo vermelho-amarelo orto, com as seguintes características: $33,7 \%$ de argila, 5,0\% de limo, 15,8\% de areia fina e $45,5 \%$ de areia grossa; $\mathrm{pH}$ de 5,$3 ; 4,4 \%$ de matéria orgânica; $100^{+}$ $\mathrm{mg} / \mathrm{ml}$ de TFSA de $\mathrm{P}, 378 \mathrm{mg} / \mathrm{ml}$ de TFSA de K, 4,2 e.mg/ $100 \mathrm{ml}$ de $\mathrm{Ca}^{++}, 1,2$ e.mg/100 ml de TFSA de $\mathrm{Mg}++$ Não se detectou alumínio. $O$ solo pertence à classe textural areno-argiloso.

Foram aplicados os seguintes tratamentos: a) trifluralin ( $\alpha, \alpha, \alpha$-trifluoro2,6-dinitro-N,N-dipropil-p-toluidina) ( ${ }^{1}$ ) a 0,86 kg; b) EPTC (etil-di-n-propil-tiolcarbamato) $\left({ }^{2}\right)$ a $3,6 \mathrm{~kg}$, ambos em pré- plantio com incorporação (PPI); c) chloroxuron [3-p-(p'clor ofen oxi)-fenil-1,1-dimetil-uréia ] ( ${ }^{3}$ ) a 6,4 kg; d) DCPA (éster dimetllico do ácido tetracloroter eftálico ( ${ }^{4}$ ) a $7,5 \mathrm{~kg}$; e) diphenamid (N-N-dimetil2,2 -difenilacetamida $\left({ }^{5}\right)$ a $\left.2,5 \mathrm{~kg} ; \mathrm{f}\right)$ pendimethalin $[\mathrm{N}$ (1-etilpropil)-3,4 di metil 2,6 dinitrobenzenamina] $\left({ }^{6}\right)$ a 1,15 $\mathrm{kg}$; g) diur on [ 3-( 3,4 -diclorofen il) -1,1dimetil-uréia] (7) a 1,6 kg, todos em préemergência (PRE) $e^{\cdot h}$ ) sem herbicida Doses de ingrediente ativo por hectare.

Os tratamentos $a$ e b foram aplicados no dia 17 de agosto de 1976 e, a seguir, incorporados com enxada à profundidade de $0,10 \mathrm{~m}$. O plantio dos bulbos se fez no dia seguinte e a aplicação dos herbicidas de PRE, no dia 20.

As parcelas mediam $2,50 \mathrm{~m} \times 3,00$ $\mathrm{m}$, com 4 linhas espaçadas de $0,60 \mathrm{~m}$, duas por variedade, em delineamento de blocos ao acaso e quatro repetições. Os bulbos foram plantados a $0,20 \mathrm{~m}$ nas 1 inhas e a $0,15 \mathrm{~m}$ de profundidade.

Foram feitas contagens aos 20 e 56 dias após o plantio, registrando-se o número de brotações dos bulbos.

Aos 37 dias, fez-se a contagem de mato e as espécies que ocorreram em maior número no experimento foram: capim-de-colchão (Digitaria horizontalis Willd.), capim marmelada (Brachia-ria plantaginea Link Hitch), capim-pédegalinha (Eleusine indica L. Gaertn.), trevo (Oxalis oxyptera Brog.), picão branco (Galinsova parviflora Cav.) ocorrendo, ainda, outras folhas largas. O tratamento sem herbicida foi capinado aos 59 dias após o plantio.

As hastes foram colhidas à medida que as primeiras flores iam se abrindo, sendo realizadas colheitas aos 75,78 , 82, 84, 86, 90, 93, 97 e 104 dias após o plantio.

Foram medidos os comprimentos da inflorescência e do segmento entre o último nó e a primeira flor e obtidos os pesos de matéria fresca das hastes florais colhidas. 


\section{RESULTADOS E DISCUSSAO}

Os números de bulbos que emitiram brotação, bem como o número de brotos, em contagens realizadas aos 20 e 56 dias após o plantio, estão no quadro 1 .

Verificou-se inicialmente uma severa inibição de brotamento dos bulbos pelo EPTC em relação aos demais tratamentos. Nestes, a maior parte das plantas nasceu até os 20 dias após o plantio, ao passo que, com o EPTC, a quase totalidade das plantas que nasceram, o fizeram entre 20 e 56 dias. Além de causar atraso no brotamento dos bulbos, o EPTC também reduziu o número total de bulbos brotados e hastes florais. Aparentemente, os outros tratamentos não apresentaram qualquer efeito de inibição ou redução do número de plantas até os 56 dias. A porcentagem de bulbos brotados da variedade rosa crespa foi superior à da branca crespa.

Os resultados de controle de mato pelos herbicidas, aos 37 dias estão no quadro 2.

A ocorrência de trevo na área do experimento não foi uniforme, mas mes mo assim há uma indicação de controle pelo trifluralin, EPTC, chloroxuron e pendimethalin.

Houve acentuada predominância de gramineas que foram controladas em niveis de $83 \%$ e $46 \%$ pelo EPTC e chloroxuron, respectivamente, e em níveis acima de $90 \%$ pelos demais.

No caso de dicotiledôneas, convém ressaltar que o picão branco apresentou uma frequência bem maior nos tratamentos com trifluralin e EPTC do que na testemunha, em virtude do excelente controle das gramíneas, o que eliminou a competição dessas espécies. Além disso, o picão branco é uma espécie resistente à ação desses herbicidas (4). Daí a indicação de controle zero nesses tratamentos. No caso do DCPA, não houve controle, mas o número de plantas de picão branco foi semelhante ao da testemunha.
O número total de hastes florais colhidas e seus respectivos pesos de matéria fresca estão no quadro 3.

Os números de hastes florais, em cada colh eita, estão na figura 1 .

Para a variedade rosa crespa, ape nas o EPTC causou redução significativa do número e peso de hastes. Para a variedade branca, houve reduções significativas de peso com os tratamentos trifluralin, EPTC, chloroxuron e pendimethalin.

Reduções de produção já foram verificadas anteriormente.com o uso de EPTC (8), trifluralin $(13,14)$ e chloroxuron (13), mas em outros experimentos, nenhum efeito fitotóxico foi verificado pelos dois primeiros $(10,15)$.

As maiores produções e melhores populações de plantas foram do tratamento testemunha, o que deve ser atribuído ao fato do mesmo ter sido capinado aos 59 dias após o plantio. A competição das plantas daninhas presentes nesse período, aparentemente não prejudicou o desenvolvimento de qualquer das variedades de gladíolo, o que pode ser verificado pelo pico de produção aos 78 dias, para a variedade rosa crespa (figura 1). No caso da variedade branca crespa que apresentou florescimento mais tardio, primeira colheita aos 82 dias, a produção máxima de flores foi atingida aos 90 dias em todos os tratamentos, verificando-se aí o pico de produção da testemunha.

Nos tratamentos com trifluralin e pendimethalin, a produção total de hastes florais foi bastante baixa em relação à testemunha, diferindo significativamente no caso da variedade branca crespa. Considerando o excelente controle de plantas daninhas por esses tratamentos, pode-se atribuir algum efeito fitotóxico dos herbicidas, ocasionando redução do número de hastes florais e respectivo peso das duas variedades.

Em relação aos comprimentos do último internódio e o da inflorescência, com excessão do EPTC, não houve influência dos tratamentos durante $\mathrm{O}$ 
Quadro 1. Número total de bulbos que emitiram 1, 2 e 3 brotaçōes em contagens aos 20 e 56 dias após o plantio, no experimento com herbicidas em gladiolos em solo areno-argiloso. Totais de quatro repetiçóes.

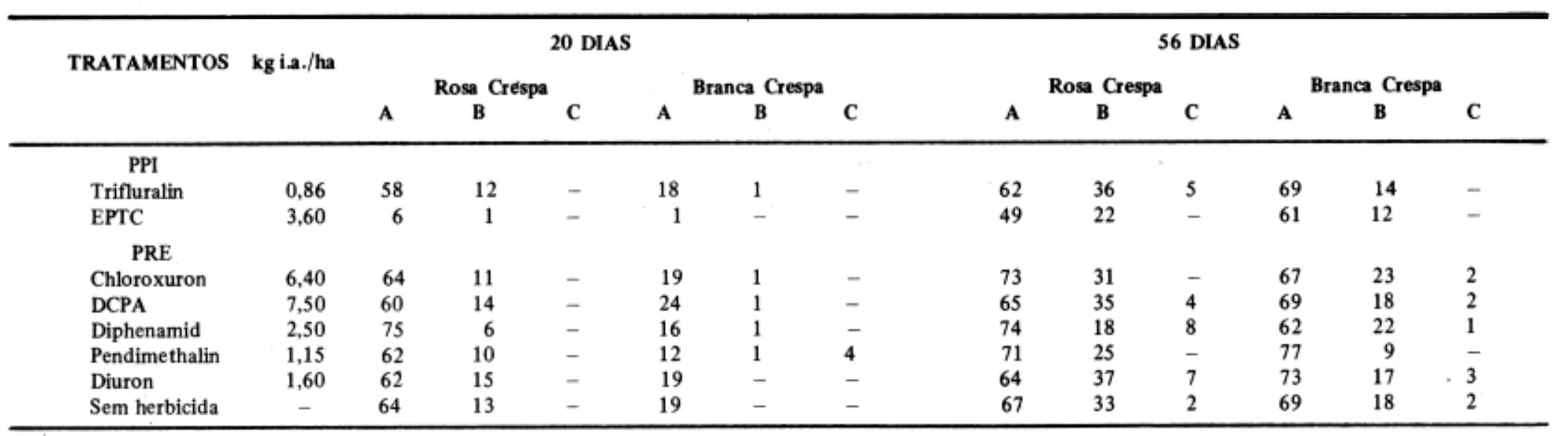

A $-\mathrm{N}^{\circ}$ de bulbos com uma brotação

$\mathrm{B}-\mathrm{N}^{\circ}{ }^{\circ}$ de bulbos com duas brotações

$\mathrm{C}-\mathrm{N}^{\circ}$ de bulbos com três brotaçōes

Quadro 2. Resultados do controle de mato, aos 37 dias, no experimento de herbicidas em gladiolos, em solo areno-argiloso, no Centro Experimental de Campinas. Médias de quatro repetiçoes.

\begin{tabular}{|c|c|c|c|c|c|c|c|c|c|c|c|}
\hline TRATAMENTOS & kgi.a./ha & $\begin{array}{l}\text { Picão } \\
\text { branco }\end{array}$ & Trevo & Cururu & $\begin{array}{l}\text { Capim-pé- } \\
\text { de galinha }\end{array}$ & $\begin{array}{l}\text { Capim } \\
\text { colchão }\end{array}$ & $\begin{array}{l}\text { Capim } \\
\text { arroz }\end{array}$ & $\begin{array}{l}\text { Capim } \\
\text { marmelada }\end{array}$ & $\begin{array}{l}\text { Folhas } \\
\text { largas } \\
\text { (-trevo) }\end{array}$ & Gramíneas & Geral \\
\hline & & $\%$ & $\%$ & $\%$ & $\%$ & $\%$ & $\%$ & $\%$ & $\%$ & $\%$ & $\%$ \\
\hline \multicolumn{12}{|l|}{ PPI } \\
\hline Trifluralin & $0,86 \mathrm{~kg}$ & 0,0 & 97,27 & 100 & 99,98 & 93,04 & 86,36 & 96,55 & 3,08 & 95,18 & 83,23 \\
\hline EPTC & $3,60 \mathrm{~kg}$ & 0,0 & 90,91 & 90,91 & 99,88 & 87,34 & 9,09 & 83,45 & 0,0 & 82,57 & 71,46 \\
\hline \multicolumn{12}{|l|}{ PRE } \\
\hline Chloroxuron & $6,40 \mathrm{~kg}$ & 43,48 & 75,45 & 96,97 & 0,0 & 56,96 & 45,45 & 69,66 & 70,77 & 45,87 & 49,10 \\
\hline DCPA & $7,50 \mathrm{~kg}$ & 0,0 & 57,27 & 100 & 99,98 & 100 & 95,45 & 93,79 & 49,23 & 97,25 & 91,02 \\
\hline Dyphenamid & $2,50 \mathrm{~kg}$ & 78,26 & 20,91 & 100 & 100 & 96,20 & 95,45 & 90,34 & 80,00 & 95,18 & 93,21 \\
\hline Pendimethalin & $1,15 \mathrm{~kg}$ & 52,17 & 78,18 & 100 & 99,99 & 98,73 & 100 & 79,31 & 83,08 & 92,43 & 91,22 \\
\hline Diuron & $1,60 \mathrm{~kg}$ & 100 & 50,00 & 100 & 99,95 & 95,57 & 77,27 & 89,66 & 100 & 92,66 & 93,61 \\
\hline Sem herbicida & n. $0 / \mathrm{m}^{2}$ & 14,38 & 68,75 & 20,63 & 68,75 & 98,75 & 13,75 & 90,63 & 40,63 & 272,50 & 313,13 \\
\hline
\end{tabular}




\begin{tabular}{|c|c|c|c|c|c|}
\hline \multirow[t]{2}{*}{ TRATAMENTOS } & \multirow[t]{2}{*}{ kg i.a./ha } & \multicolumn{2}{|c|}{ ROSA CRESPA } & \multicolumn{2}{|c|}{ BRANCA CRESPA } \\
\hline & & $\mathrm{n}^{\circ}$ & $\mathrm{kg}$ & $\mathrm{n}^{\circ}$ & $\mathrm{kg}$ \\
\hline \multicolumn{6}{|l|}{ PPI } \\
\hline Trifluralin & 0,86 & $30,75 \mathrm{a}$ & $2,087 \mathrm{~b}$ & 16,00 & $0,707 \mathrm{c}$ \\
\hline EPTC & 3,60 & $20,00 \mathrm{~b}$ & $0,865 \mathrm{c}$ & 15,25 & $0,575 \mathrm{c}$ \\
\hline \multicolumn{6}{|l|}{ PRE } \\
\hline Chloroxuron & 6,40 & $33,75 a$ & $2,280 \mathrm{ab}$ & 20,00 & $0,672 \mathrm{c}$ \\
\hline DCPA & 7,50 & $33,50 a$ & $2,370 \mathrm{ab}$ & 18,50 & $0,847 \mathrm{abc}$ \\
\hline Diphenamid & 2,50 & $31,75 \mathrm{a}$ & $2,350 \mathrm{ab}$ & 16,50 & $0,835 \mathrm{abc}$ \\
\hline Pendimethalin & 1,15 & $28,50 \mathrm{ab}$ & $2,205 \mathrm{ab}$ & 16,75 & 0,765 bc \\
\hline Diuron & 1,60 & $34,50 a$ & $2,470 \mathrm{ab}$ & 21,50 & $1,170 \mathrm{ab}$ \\
\hline Sem herbicida & - & $34,50 \mathrm{a}$ & $2,885 \mathrm{a}$ & 22,00 & $1,207 \mathrm{a}$ \\
\hline F. & & $7,06^{* *}$ & $13,53^{* *}$ & 2,32n.s. & $6,84^{* *}$ \\
\hline C.V. $\%$ & & 11,86 & 14,52 & 18,58 & 20,56 \\
\hline
\end{tabular}

(**) Significativo ao nível de $1 \%$ de probabilidade (Teste de Tukey)

n.s. Não significativo.

período de florescimento. Verificou-se que as plantas da variedade rosa crespa, que floresceram no período de 75 a 82 dias após plantio, eram mais vigorosas, decrescendo os tamanhos das hastes para o final, havendo proporcionalidade entre os pesos e essas medidas. O mesmo se verificou para a variedade branca crespa, cujo florescimento se iniciou aos 82 dias. As medidas do $1 .^{\circ}$ internódio e da inflorescência das 2 variedades não apresentaram diferenças notáveis nas primeiras colheitas.

No caso do EPTC, as plantas que emitiram haste floral, após os 78 dias, não mostraram qualquer efeito inibitório do herbicida, chegando mesmo a apresentar comprimentos maiores, em média, do último internódio e da inflorescência. Isso sugere que, com a dissipação do EPTC do solo, atingindo níveis sub-tóxicos, possa ter havido mesmo algum estímulo de crescimento posterior.
As medidas desses parâmetros, para a variedade branca crespa, apresentaram grande oscilação, não se verificando qualquer efeito do EPTC, além de atrasar o florescimento.

O diuron, que apresentou melhor controle geral, aparentemente não afetou o desenvolvimento do gladíolo, com produção e número de plantas semelhantes ao tratamento testemunha. Sua tolerân cia pelo gladíolo já fora' observada desde o seu surgimento apresentando controles excelentes de plantas daninhas $(2,3,7,12)$.

Para os demais tratamentos, a redução na produção de hastes florais em relação à testemunha pode ser atribuída à competição ocorrida pelas plantas daninhas não controladas, uma vez que esses tratamentos não receberam nenhuma capina. O controle diferencial de plantas daninhas ocorrido no experimento sugere o uso de misturas de diferentes herbicidas, o que ampliaria o espectro de controle. 

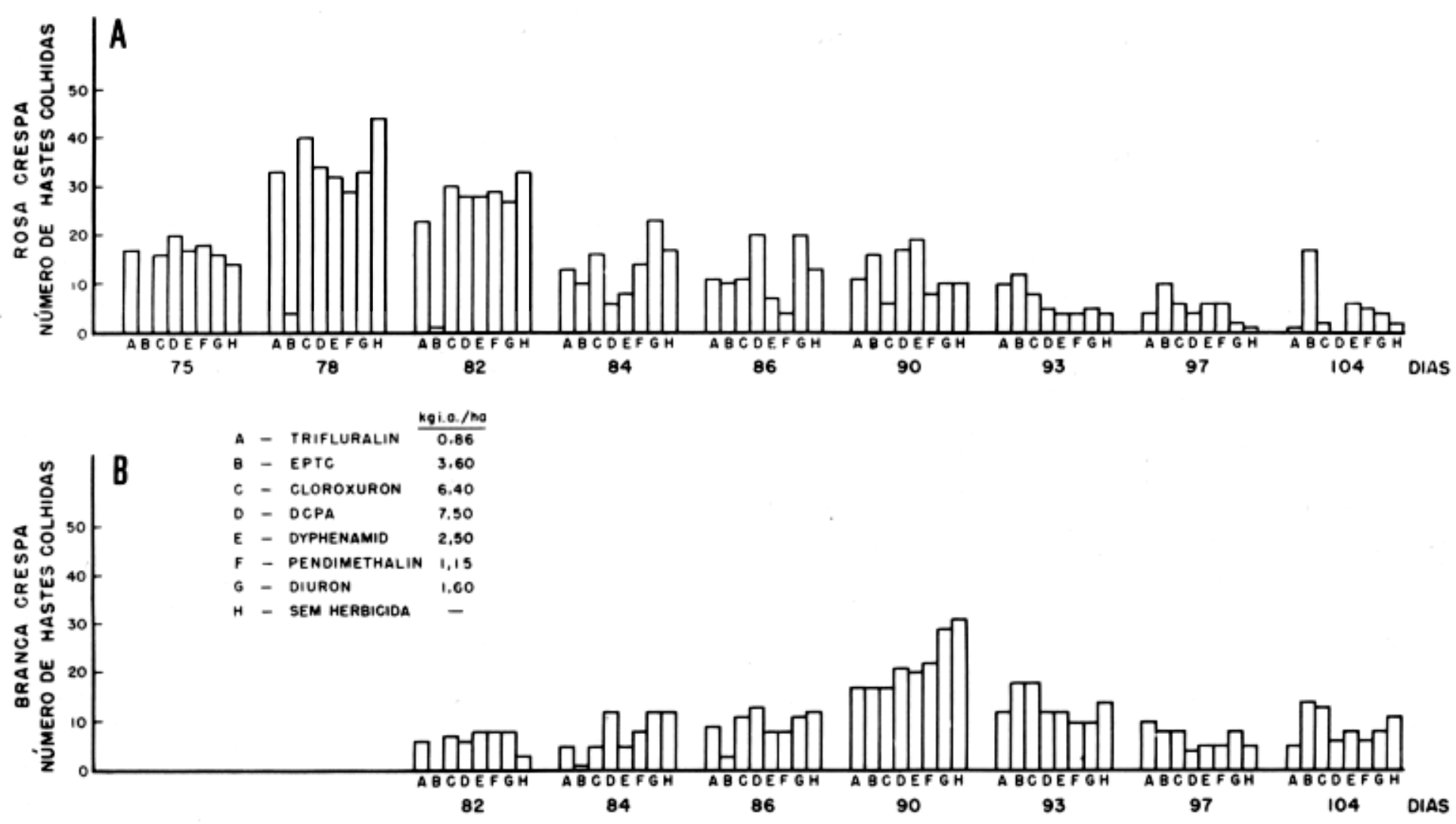

Figura 1. Número de hastes forais de gladiolos, das variedades Rosa crespa (A) e Branca crespa (B), colhidas no experimento de herbicidas, em solo areno-argiloso. 
Em todos tratamentos, verificouse que o número de hastes florais foi aproximadamente semelhante em cada colheita, à excessão do EPTC. O florescimento, neste tratamento, foi retardado nas duas variedades. $\mathrm{Na}$ rosa crespa, apresentou um número crescente de hastes floridas, ao contrário dos demais tratamentos, atingindo um máximo na última colheita, aos 104 dias. Para a variedade branca crespa, a defasagem não foi tão acentuada, como se pode verificar na figura 1.

\section{LIT ERATURA CITADA}

1. Bing, A. Gladiolus weed control experiments. 1954. The Gladiolus: 78-82, 1955.

2. Bing, A. Gladiolus weed control experiments. The Gladiolus: 207-209, 1957.

3. Butterfield, N.W. Report for weed control in gladiolus for 1965. The Gladiolus: 144-153, 1966.

4. Deuber, R.; Forster, R.; Camargo, L.S.; Scaranari, H.J.; Martins, F.P. \& Alves, S. Ensaios com Herbicidas em Cultura de Cenoura (Daucus carota L.). Campinas, Inst. Agron., 1975. 31p. (Boletim Tec. 23).

5. Eijsink, A.J.J. Contribuição a Estudos de Diagnósticos de Floricultura no Estado de Sáo Paulo. Trabalho de graduaçâo - Facul- dade de Medicina Veterinária e Agronomia Prof.Antonio Ruete de Jaboticabal, 1975.

6. Florida. Agricultural Extension Service. Chemical weed control guide. The Gladiolus: 105-110, 1962.

7. Gasiorkiewicz, E.C. The use of granular herbicides in gladiolus. The Gladiolus: 94-103, 1958.

8. Hall, B.J. Experiences with three new herbicides (CDAA, CDEC, EPTC). Aust. Weed Conf., 2, 1960. Proc., paper 59, pp.8.

9. Lavoura - Muitas flores no mercado - maio/junho de 1978.

10. Men'shov, V.V. \& Rudnik, N V. (Application of Treflan and Nitrofor in Gladioli). Khimiya v Sel'skom Khozyaistve 12:50-52, 1974. (Hortic. Abstracts 45: 4265, 1975).

11. Miranda, M.A.L. Floricultura-- Diagnóstico de Situação - Medidas corretivas. Coordenadoria de Assistência Técnica Integral. São Paulo (mimeografado). 1970.

12. Monaco, T.J. \& Jenkins, J.M. Gladiolus weed control. In. Ornamental research, 13th annual report of the Southern Nursery men's Association (1969): 69-70. (Weed Abstracts 20: 2082, 1971). NCSU, Raleigh, U.S.A.

13. Moreau, M. Essais de désherbage chimique en cultures florales de plein air. Pépiniéristes Horticulteurs Maraichers 167: 21-24, 1976.

14. Pimpini, F. Il diserbo chimico nella coltura semiforzata del gladiolo. Rivista di Agronomia 8: 335-343, 1974.

15. Wilfret, C.J. \& Burgis, D.S. Weed control in petunia, ageratum and gladiolus grown in open fields. Annual Meet. South Weed Sci. Soc., 30, U.S.A., 1977. Proc., p.197-204. 